\title{
Digital Technologies, Competitiveness and Policies: Designing an Integrative City-Based Policy Roadmap for Entrepreneurial Ecosystems
}

Authors: Cetindamar, D., Lammers, T. and Sick, N. School of Information, Systems and Modelling, Faculty of Engineering and IT, University of Technology Sydney, Sydney, Australia.

\begin{abstract}
:
This paper offers a conceptual city-based policy roadmap for policy makers who are interested in managing their entrepreneurial ecosystems. The literature lacks specific policies bringing together both technological developments and entrepreneurial activities at city level, even though recent studies point out the role of policies for entrepreneurial ecosystems in order to build entrepreneurial economies. Given the wide opportunities arising from digital technologies for economic growth, policy makers need to identify feasible frameworks to support a digitally competitive entrepreneurial ecosystem. By combining the previous literature on entrepreneurship and digital technologies within a particular urban context, this paper describes a conceptual roadmap as a tool that might help policy makers to plan the future competitiveness of their cities.
\end{abstract}

Keywords: digital technologies, entrepreneurial ecosystem, city, policy framework

\section{Introduction}

The recent entrepreneurial literature provides several dynamic factors affecting the success of an entrepreneurial ecosystem (Stam, 2015). However, researchers point out the role of local conditions and bottom-up processes and they advise customization of policies rather than copying successful policies applied in other regions such as in Silicon Valley (Alvedalen \& Boschma, 2017; Isenberg, 2011). More importantly, they call policy makers for creating policies for entrepreneurial regional economy rather than for entrepreneurship alone (Thurik et al., 2013). In fact, Stam (2018) specifically calls for policies for an entrepreneurial economy by understanding local knowledge through the lens of an ecosystem and involvement of the relevant stakeholders. Agreeing with such a policy approach, this paper emphasizes the need for a city-based tool that integrates both entrepreneurship and technology policies to flourish and generate innovations for the overall performance of the ecosystem.

Due to rapid urbanization, cities have become a major site of competitiveness (Roger et al., 2015). As a United Nations (2017) report summarizes, cities account for 70\% of global gross domestic product in 2016 . Thus, cities are becoming key platforms for policy makers. In parallel to increased economic importance of cities, policy makers are also expected to face new challenges arising from the radical transformation of cities into "smart cities" due to recent technological changes.

Digital technologies such as big data analytics and 3-D printing are attracting attention from entrepreneurs and policy makers for different purposes. These technologies could help policy makers effectively and efficiently manage their cities in addition to being a source of economic and social growth. The literature presents a number of studies on digital technologies and entrepreneurial policies carried out independently by disciplines ranging from operations management to entrepreneurship. Thus, this paper offers a short literature review and then proposes a conceptual roadmap tool customized for the use of digital entrepreneurial ecosystem at city level. Roadmaps are widely known for being a strategic decision process framework that supports enterprise innovation activities. They have attracted the interest of an increasing number of academics and practitioners, and have been applied in many different industrial sectors and organizations (Lee et al., 2007; Amer and Daim, 2010). For example, Lee et al. (2013) developed an integrated roadmapping process for services, devices and technologies capable of implementing a smart city development R\&D project in Korea. Similar to their work, this paper targets to develop an integrative policy roadmap as an effort to both develop and commercialize digital technologies at city level and benefit from these technologies locally.

The paper has four sections. After this short introduction, section 2 presents theoretical discussions on digital entrepreneurial ecosystems. It starts with the introduction of entrepreneurial system and digital technologies, and then moves into the arguments showing the need for policies to establish and develop entrepreneurial ecosystems. Section 3 lays the ground for the conceptual roadmap model. The last section summarizes the paper and ends with suggestions for future research.

\section{Background on digital entrepreneurial ecosystems}

\subsection{Entrepreneurial Ecosystems}


Entrepreneurship is the process by which individuals exploit opportunities for innovation (Schumpeter, 1934), while ecosystem refers to the interconnectedness of organizations that are mutually dependent on each other's inputs and outputs (Stam, 2015). The entrepreneurial ecosystem concept emphasizes that entrepreneurship takes place in a community of interdependent actors. Even though there are discussions around the use of entrepreneurial ecosystems (Alvedalen and Boschma, 2017), this paper will use it in a pragmatic manner to refer the interlinkages of complex and dynamic actors (Oh et al., 2016). Considering that entrepreneurship is an important source of innovation, productivity growth and employment (WEF, 2013), many countries are searching ways of creating an amiable environment for entrepreneurship to flourish in a competitive world (Autio et al., 2018).

Seemingly paradoxical, there is a revival of emphasis on regions and on the importance of geography in economics in the 21 st century despite the extent to which globalisation has turned our world into a "global village" (Henderson, 1995). In this context, the entrepreneurial ecosystem approach has commonalities with other established concepts, in particular regional innovation systems (Cooke, 1992) and regional innovation management (Kriz et al., 2016: Autio et al., 2018). Similar approaches highlighting the importance of the regional environment as a driver of innovation are industrial districts, industrial clusters, and innovative milieus (Asheim et al., 2011). These concepts are grounded in Marshall's work (1898) on industrial districts where economic value results from the interplay of institutions, agglomeration economics and cooperation of firms. The original definition of industrial district is the spatial concentration of firms operating in one particular industry in a town or a few neighbouring small towns where especially small firms cooperate with each other and are embedded in the local community (Richardson, 1995).

The attractiveness of a region is a function not only of geographical and socio-economic factors taken in isolation, but also of a complex interplay of external economies characteristic of a prior industrial agglomeration (Richardson, 2015). For example, the sources of agglomeration economies arise from local concentration of customers, which reduce overhead and infrastructure costs; economies of scale in production or distribution; sufficient demand to warrant the provision of specialized infrastructure; and deep and diversified pool of workers sufficient to realize a more specialized local division of labour. In the same way, these economies are product of the use of specialized equipment and services; opportunities for bulk purchasing; joint research; organized markets for finished products; reduced cost of negotiating and monitoring contracts; and existence of specialized brokers or specialized machinery producers (Henderson, 1995; Marshall, 1898).

Agglomeration economies refers to the unit cost reductions of a firm arising from internal and external economies when it is located together with relatively dense clusters of other firms or specialized resources rather than located elsewhere. These economies fall into one of the following three groups (Hoover, 1975). The first one, internal economies, is related to the idea of economies of scale and caused by the increase of the firm scale of production at one point. The second one, localization economies, is externalities associated with the presence of many other producers in the same industry or sector. The last one, urbanization economies, is externalities associated with the co-presence of firms from diverse industries. In other words, urbanization economies are applicable to all firms in all industries, arising from the enlargement of the total economic size of that location for all industries taken together. Over time, agglomeration economies have become the crucial element for regional and economic policies (Hoover, 1975). Along these lines, Leydesdorff and Deakin (2011) pointed out that cities are "key components of innovation systems" because of their dense networks between academia, industry and government. Cities thus provide exceptional circumstances for collaborations across the triple helix as an essential prerequisite for regional development (Katz and Wagner, 2014).

Cities / metropolitan areas are not only be the base for the accumulation of ubiquitous assets, economic, physical, as well as networking (Newman, 2017), but they are the implementation arena for many digital technologies. In the past, there have been studies on the economic development around technologies developed and utilized at cities that forms the base of a rich literature on Technopolis (Phillips, 2006). It seems history repeats itself with new digital technologies. The goal for policy makers could be to find ways to identify the potential industrial clusters in their cities and then to support entrepreneurship ecosystems around them in order to efficiently utilize digital technologies.

This new type of ecosystems inspired academics to bring forward a new concept: digital entrepreneurial ecosystems, defined as "eentrepreneurial activities that optimize the utilization and reconfiguration of digital infrastructure in the form of new systems, new platforms, and new networks." (Susan and Acz, 2017). The study of Du et al. (2018) clearly shows that studies on digital entrepreneurship have mainly focused on firm-level characteristics and largely overlooks the external environment, i.e., the digital entrepreneurial ecosystem. That is 
why academics have recently started to point out new policy and strategy related issues arising from digital ecosystems (Weill \& Woerner, 2018).

\subsection{Digital technologies}

Digital technologies are general-purpose technologies and have the potential to change all aspects of production, consumption, and government services in our daily life. They will have a massive impact on entrepreneurial ecosystems not only by providing new capabilities and business models but also by affecting their environment and its surrounding regulating frameworks (see Figure 1). Current trends in digital technology development include the Internet of Things (IoT), enhanced data analytics, artificial intelligence (AI) and virtual reality. Companies increasingly realize that digital transformation will become an imperative in today's competitive market (Newman, 2017). Currently, the pace of change provoked by digital technologies is not only accelerating, but also widening. For example, it will not only enable people to increase their capabilities but also increase organizational innovation as well as integrate whole ecosystems and supply chains (Groopman et al., 2017). These macro trends will bring with them massive regulatory challenges to provide stability on topics such as AI and cyber security (Dia, 2016; Hellwig, 2017). Research goes as far as claiming that advances in digital technology could automate half of today's work by 2055 (Manyika et al., 2017).

\section{*** Insert Figure 1: Dimensions of digital technology impact *** Source: Authors.}

Originally created in the context of manufacturing in Germany, the term Industry 4.0 describes a new trend of automation and data exchange enabled through the IoT, cyber-physical systems and cloud-computing (Jasperneite, 2012). This technological shift will have a significant impact on global competitive frameworks, as companies change to become integrated networks with high automation levels and real-time data access (Brettel et al., 2014). Increasing technologically enabled customer demands put further pressure on organisations' competitiveness (Kumar, 2017). The impacts of this shift go beyond manufacturing. It will provide business opportunities and challenges in areas such as logistics, smart services IT infrastructures, and workforce management (Schlaepger et al., 2014). Thus, policy makers should consider the ways of integrating digital technologies into their ecosystem plans.

For this purpose, the smart city approach provides a valid starting point to design digital entrepreneurial ecosystems. The concept of smart cities arose from smart specialisation strategies for regions, where 1) the competitive advantages of the region is identified, 2) R\&D and innovation efforts are targeted in these areas, and 3 ) based on that, a vision for regional innovation is developed (OECD, 2013). Smart cities apply these principles on a city (metropolitan) level, mostly with a focus on IT as an enabler (Caragliu et al., 2011). Having just emerged with the rise of IT, there is no coherent definition of a smart city yet, but rather common elements of existing smart city concepts (Albino et al., 2015). However, key elements consist of a technology-based infrastructure, a closely connected network of partners, a creative class, and an urban development plan for economic and social sustainability (Hollands, 2008).

\subsection{Policies for entrepreneurial ecosystems}

The last decade has witnessed the rise of technology-based entrepreneurs who managed to build companies based on the use of emerging digital technologies. However, the pure availability of digital technologies in a particular country does not guarantee to establish successful companies and economic growth. This is why academics and policy makers who are concerned with market failures of new technologies are increasingly calling for policy interventions (Rodrik, 2008). In fact, studies focusing on digital platform ecosystems have recently raised the market failure concerns not for policy makers but also for leaders in digital platform ecosystems (Helfat and Raubitschek, 2018). Digital technologies supply a platform where companies such as Apple build many products and services through partners, eventually building an ecosystem of companies raising against other ecosystems (Teece, 2018). However, leading and managing such a platform is not easy for companies, since they need to design, manage, and alter ecosystems as conditions change in dynamic environment. As the work of Helfat and Raubitschek (2018, p. 1342) describes "platform leaders operate in a world of market failure characterized by imperfect information about relevant choices and the outcomes of making them, in a setting that calls for highly interdependent decisions due to the frequent presence of crossside (or indirect) network effects." In order to overcome this market failure, Helfat and Raubitschek suggest platform leaders to develop innovation capabilities, environmental scanning and sensing capabilities, and integrative capabilities for ecosystem orchestration. It seems similar capabilities are relevant for policy makers that try to establish a technology-based platform for all stakeholders to benefit. 
Further, Stam (2018) makes a convincing argument that policies work if they focus on building entrepreneurial ecosystems for creative destruction. In other words, these policies will enable the creation of innovative start-up that help economies to diversify their productive structures in order to sustain economic growth. Structural change helps economic development by transferring the economy's limited resources from low-productivity activities to high productivity activities (Rodrik 2008). That is why Stam (2018) argue that supporting new innovative start-ups can overcome two key government failures used against policy making: (1) the most efficient and effective allocation of (public) resources in the future and (2) the government's liability to rent seeking by vested interests (Mueller, 2003).

For a successful policy, besides the focus on start-ups, Stam (2018) argues that two types of input are needed: (1) data on the nature of the innovative start-ups themselves and their context and (2) consultation of and collaboration with public and private stakeholders. Only then, policy makers might find develop direct levers for policy intervention and their implementation through the help of stakeholders.

Regarding the first input, companies are located in certain regional or urban environments with varying contextual factors. Big cities around the world are trying to leverage on their advantages and overcome their city-specific challenges to attract start-ups and provide an optimal breeding ground for digital entrepreneurship. The use of digital technologies to generate competitive advantage is, among others, a critical factor affecting the success of an entrepreneurial ecosystem. However, researchers point out the role of local conditions and bottomup processes and they suggest customization of policies for the respective entrepreneurial regional economy (Stam, 2015). Thus, a comprehensive policy should integrate both entrepreneurship and technology policies in order to flourish and generate innovations for the overall performance of the ecosystem.

The second input requires democratic integration of all stakeholders. A recent report (Rissola \& Sörvik, 2018) highlights how EU policy makers establish ecosystem orchestration mechanisms to generate interactions among stakeholders and improve their digital capabilities. In 2016, the EU launched Digital Innovation Hubs at regional level because on average in the EU, only about 1 out of 5 companies has highly digitised while there are still large disparities between regions in the take-up of information and communication technologies (ICTs) by small and medium sized companies. Hubs target these firms embedded in different regional context and try to orchestrate ecosystem by helping these firms to understand and utilize digital opportunities. As the report confirms, this initiative of establishing hubs is in line with the EU "smart specialization strategy" (3S) that aims to create specialization of regions. In other words, each region will build strengths on certain industrial, innovation and technological activities through local stakeholder engagements as promoted by the EU and OECD (2012). The study of Radosevic and Stancova (2018) calls this 3S as the largest innovation policy experiment in the world. Such approaches help identifying areas of discovery and mobilising stakeholders to know where the greater potential for regional growth is in a collaborative manner. Even EU policies force the integration of research and innovation strategies to comply with smart specialisation strategies by making this as a prerequisite in order to receive funding from the European Regional Development Fund.

The geographical unit for ecosystems could be city, region, nation, or even a group of countries such as the European Union. This paper chooses the city as a feasible unit of analysis. However, it is necessary to note that city does refer to the metropolitan area in the geographical sense. There are three main reasons for choosing the city level as the scope of investigation for policy makers. First, due to the trend of rapid urbanization, there are abundant entrepreneurial opportunities. The United Nations (2017) project the number of people living in cities to reach to more than six billion people. City population represents not only customer but also workforce, innovators, and entrepreneurs. Second, digital technologies are diffusing rapidly at cities as previous technologies have done (Phillips, 2006). Cities have also become the major unit of competitiveness and therefore policy makers at cities race with each other to build smart cities to gain competitive advantage (Cetindamar \& Gunsel, 2012; Roger et al., 2015). Third, city level analysis helps to consider a well-defined unit of location for understanding social, historical, and political fabric, which creates the base for an entrepreneurial ecosystem (Thurik et al., 2013).

\section{A conceptual policy roadmap tool for managing digital entrepreneurial ecosystems in cities}

\subsection{Roadmaps}

Galvin (1998) defines "roadmap" as "an extended look at the future of a chosen field of inquiry composed from the collective knowledge and imagination of the brightest drivers of change in that field (p. 803)." The 
roadmapping approach has become one of the most extensively used techniques for supporting strategic planning and innovation; it has also been widely used in public domains, in order to influence policy, research funding, and standards (Phaal \& Muller, 2009). This is due to its ability to provide a coherent, holistic, and highlevel integrated view of complex systems, while displaying the interactions between various innovation activities over time (Groenveld, 2007; Kostoff \& Schaller, 2001; Popper, 2008). Such a systems-based approach of strategic roadmapping is also potentially useful in managing and developing strategies for standardization activities in support of innovation, as a practical and operational tool for observing how standardization and other innovation activities influence each other with a more careful level of analysis.

This paper proposes an approach to build an integrative city-based policy for digital entrepreneurial ecosystems. The roadmap framework as a strategic tool might help policy makers to align the capacity of a city in digital technologies with the capacity residing in its entrepreneurship ecosystem (Cetindamar \& Gunsel, 2012). This could increase utilization of technologies and bring together a number of benefits as discussed in the following paragraphs (Cetindamar et al., 2018).

First, local governments develop economic and technology policies for future economic development. Understanding the impact of digital technologies on city competitiveness requires an understanding of decisions made by numerous stakeholders at city level. Governments, managers and researchers regularly make decisions independent of each other. Bringing them will profoundly influence each city's future development, economic fabric and national competitiveness. As Best $(2015, \mathrm{p} .4)$ argues for the industrial ecosystem in Boston: "The population of enterprises is embedded in a regional industrial ecosystem that facilitates ongoing reshuffling of the region's expertise, technology capabilities and financial resources for not only a single company but for a cluster of companies to grow fast." Managers are making critical decisions about what technologies to invest: researchers consider what scientific areas to conduct their research; policy makers search support schemes for future and invest in infrastructure and research projects. These decisions call for sound empirical research that takes into account changing contexts, technologies and stakeholders. The proposed roadmap tool contributes to the evidence base to inform decisions in this complex and changing landscape.

Second, the integrative framework will provide data in two direct ways. Firstly, the roadmap will contribute to integrative policy discussion by bringing the complementary needs of education, entrepreneurship, industrial, innovation and technological policies. Secondly, the systematic investigation will improve the systemic use of digital technologies for increasing competitiveness of companies and entrepreneurs at city level. The commercialization of science has been a national priority in many countries. The potential changes in industry and technology programs could contribute to competitiveness capacity of cities that will capture of technological opportunities, thus enabling the long-term success for city's economy and welfare.

Third, the roadmap might deliver data in indirect ways. For example, city level data on ecosystem could help to supply input for addressing complementary fields such as education. In particular, the observation of future might be instrumental in planning educational programs to align with future expectations at industrial sectors. This could be helpful in generating inclusive cities by dropping the digital divide in skills. Similarly, the integrated policy could help efficient use of resources at cities, improving the sustainability of cities. Moreover, adoption of digital technologies by companies will generate many spill over effects such as development of digital capabilities that might be transferrable to other sectors in city environment.

\subsection{Designing a policy integrated roadmap}

A generalized strategy process model comprises the following steps (Phaal et. al, 2010):

1. Vision and goals: to establish a sense of direction, in terms of a future vision and goals.

2. Appraisal of current position: to collate and assess information currently available, together with a review of current and historical strategies, activities, and performance.

3a. Assessment of external environments: to collect and assess information relating to external factors, issues, and drivers to identify opportunities and threats.

3b. Assessment of internal environments: to collect and assess information relating to internal resources, capabilities, and constraints, to identify strengths and weaknesses.

4. Generation and assessment of strategic options: to generate strategic options, identify gaps, and assess and select the options to derive strategic plans.

5. Implementation: to put the strategic plan into action.

6. Evaluation and learning: to review outcomes and disseminate results. 
This general framework targets companies but its adopted versions include national level assessments such as the standardization roadmaps for ICT system standards (Ho, 2014) or the smart city development research \& development project (Lee et al., 2013). In this paper, we customize it for the city level.

The success of an entrepreneurial ecosystem relies on local conditions and bottom-up processes, thus policies for entrepreneurial regional economy call for customization (Stam, 2018). A comprehensive policy might integrate both entrepreneurial and technology policies in order to flourish and generate innovations for the overall performance of the ecosystem.

The proposed framework/approach is not a product or technology roadmap but a policy roadmap. Roadmapping is a powerful technique that has become integral to creating and delivering strategy and innovation in many organisations. A recent work uses it to have multi-dimensional science and technology planning (Huang et al, 2014). The graphical and collaborative nature of roadmaps supports strategic alignment and dialogue between functions in the firm or organization and even between organizations.

Since entrepreneurial ecosystems are embedded within the local context, the roadmapping technique gives flexibility to policy makers by allowing the alignment of specific needs at all levels, including functional, organisation-wide and even collaboration between organisations. Additionally, roadmapping draws on collaborative strategy making. Decision-making is consensus-based and transparent, facilitating key stakeholders to take roadmaps forward and apply according to their need.

This paper aims to expand the generic roadmap in such a way that it will satisfy two policy rules for entrepreneurial ecosystems offered by Stam (2018): (1) the roadmap should deliver data about the nature of the innovative start-ups themselves and their context and (2) the roadmap will rely on consultation of and collaboration with public and private stakeholders.

Thus, this paper proposes small modifications to the 6-step generic roadmapping process (Phaal et al.) to comply with these two rules. The layers of the city-based policy roadmap consist of policy, industry and technology. In the proposed model, Step 1, 5 and 6 are same as originally designed, while the remaining steps are modified as shown in Figure 1.

Inspired by Ho (2014), we call three steps in the middle (Steps 2, 3 and 4) as the "input and analysis stage" of the road mapping process. Activities in these steps bring together the analysis and assessment of policy goals and capacities of a city in the form of industrial and technological capacities, with an emphasis on start-ups. This could fulfil the first policy rule mentioned above.

During the input and analysis stage, we particularly suggest an in-depth roadmap exercise for each particular technology field. This is because, even though technologies such as artificial intelligence and block chain are under the title of digital technologies, each of them are different in terms of the involved technologies, products and services. This necessitates a separate roadmapping exercise for each technology field. This detailed roadmapping approach is also in line with the EU's strategic call for building smart specializations. In other words, we argue that each urban region has a few core capabilities as targeted in EU's smart specialization strategies. That is why it is critical to determine key strategic orientations for the city to enhance its competitiveness along its capabilities.

The second policy rule could be fulfilled by the inclusion of macro-micro analysis at each investigation level, industrial, policy and technological. While macro-level analysis refers to the assessment of technological and entrepreneurial capacities of a city at the aggregate level, the micro-level covers the assessment of capacities of individual stakeholders/organizations (i.e. entrepreneurs, firms, innovators). This stakeholder approach could facilitate the communication among entrepreneurial ecosystem actors (industry bodies, suppliers, researchers, innovators, investors, entrepreneurs, and governments). Hence, their policy decisions and technology strategies might contribute to a healthy collaborative endeavour for creating future (Tan et al., 2015).

*** Insert Figure 2. Policy roadmap for an entrepreneurial ecosystem *** Source: Authors, based on Phaal et. al. (2010).

In our model, the micro-macro analysis requires gathering data for current city levels of industry and technology capacities as well as potential trends at the national/international level. The inclusion of trend analysis on international level is particularly important to position city's ecosystem in global networks. As Radosevic and Stancova (2018) criticize, EU's smart specialization strategies ignore the need to couple with international 
knowledge and production networks and thus limit the effectiveness of R\&D-based growth. In other words, Step 2 and 3 together focus on the analysis of indicators for the specific technology field such as AI, including: patents, scientific publications, infrastructure (incubators, technoparks, etc.), creative local labour, graduates in digital fields, research \& development (R\&D), and start-ups.

Besides capacities, a long-term trend analysis could bring wide range of data about technologies, industries, and policies. Thus, trend analysis again requires the consideration of micro-macro analysis. That means, the trend data should come not only from city level resources but also from national and international studies. Policies at city level need to pull together data from different policy documents. Each city or nation might have different policies and call them differently, but roadmapping activity should analyse all existing policies ranging from industry, education, technology, competitiveness, innovation, entrepreneurship, start-up, to smart city policies. The goal in aligning different policies is to find out policy goals and specific programs designed for the particular technology at hand. Similarly, the industrial base of a city might help to bring rich data on finding opportunities for integrating technology and industrial capacities at the local level. For example, AI is expected to influence medical sector, so roadmap activity could focus one technology and one industry. This might allow the selection of lists of services and products produced in the city by those particular industry actors. Then, there is need to collect national and/or international trend analyses for industries, technologies and policies. These trend analyses might rely on secondary resources such as forecast studies as well as customized data collection efforts such as a Delphi survey with specific technical experts from industrial, academic, R\&D backgrounds.

\section{Concluding remarks}

This paper has outlined some of the recent studies regarding entrepreneurial ecosystems and digital technologies. To create a competitive environment for flourishing digital entrepreneurial ecosystems, there is an urgent need to align cities' entrepreneurial and technology policies. Since this area is still largely unexplored, this paper focuses on finding a possible mechanism in aligning policy agendas around digital technologies and entrepreneurial ecosystems. Then, drawing on literature, we propose a conceptual tool for policy makers: an integrated city-based policy roadmap to manage city based policies in order to support the creation and commercialization of digital technologies at the city level.

A systemic perspective of an integrated city-based policy roadmap could be instrumental in finding ways of how best to align digital technologies with entrepreneurial capabilities at local ecosystems. This local data could prevent to pursue unrealistic trends set by global hype on some digital technologies in general. Thus, we believe that a closely connected analysis of individual digital technologies could be of high significance in two ways. First, both managers and entrepreneurs might improve their utilization of digital technologies by understanding the complex relationships between digital technologies and entrepreneurs. For example, the commercialization of science has been a national priority in many countries like Australia (e.g. the Australian Government's Science and Research Priorities). The effective adoption of digital technologies by companies, particularly startups, could result not only in immediate economic benefits, but it could also generate many spill over effects. One such spill over effect is the transfer of digital capabilities to other sectors in city environment, contributing to the economic and social growth of cities. Another one is the increased collaboration among business and researchers in innovation ecosystems at cities.

The conceptual framework presented here needs to be further developed and tested, e.g. using case studies. Future studies should help to develop policy agenda in a number of ways. They might develop metrics to assess strategic fit between ideal city policies and their realization at city level. They could raise the issue of the alignment of capacities at digital technology and entrepreneurship for a healthy economic growth at cities. They might also conduct empirical studies to collect data and search for ways of streamlining and enriching the proposed framework. In particular, comparative studies might enrich the framework and increase the generalizability of the findings driven from the studies of individual cities.

Acknowledgements:

We are grateful to the attendees of PICMET 2018 who have given comments on the early version of this paper.

\section{REFERENCES}

Albino,V., Berardi, U. and Dangelico R.M., (2015). Smart cities: Definitions, dimensions, performance, and initiatives, Journal of Urban Technology, 22 (1), 3-21. 
Alvedalen, J., \& Boschma, R. (2017). A critical review of entrepreneurial ecosystems research: Towards a future research agenda. European Planning Studies, 25 (6), 887-903.

Amer, M., \& Daim, T. U. (2010). Application of technology roadmaps for renewable energy sector. Technological Forecasting and Social Change, 77 (8), 1355-1370.

Asheim, B. T., Smith, H. L., \& Oughton, C. (2011). Regional innovation systems: theory, empirics and policy. Regional Studies, 45 (7): 875-891.

Attaran, M. (2017). The internet of things: Limitless opportunities for business and society. Journal of Strategic Innovation and Sustainability, 12 (1), 10-29.

Autio, E., Nambisan, S., Thomas, L. D. W., and Wright, M. (2018). Digital affordances, spatial affordances, and the genesis of entrepreneurial ecosystems, Strategic Entrepreneurship Journal, 12:72-95.

Brettel, M., Friederichsen, N., Keller, M., \& Rosenberg, M. (2014). How virtualization, decentralization and network building change the manufacturing landscape: An industry 4.0 perspective, International Journal of Mechanical, Industrial Science and Engineering 8 (1): 37-44.

Caragliu, A., Bo, C. D., \& Nijkamp, P. (2011). Smart cities in Europe, Journal of Urban Technology, 18 (2): $65-$ 82.

Cetindamar, D., Lammers, T., \& Sick, N. (2018). Establishing Entrepreneurship Ecosystems Based on Digital Technologies: A Policy Roadmap Approach at the City Level, PICMET conference, 19-23 August, Hawaii.

Cetindamar, D., \& Gunsel, A. (2012). Measuring the creativity of a city: A proposal and an application, European Planning Studies, 20 (8): 1-18.

Cooke, P. (1992) Regional innovation systems: Competitive regulation in the new Europe, Geoforum 23 (3), $365-$ 382.

Dia, H. (2016, March). Who (or what) is behind the Wheel? The Regulatory Challenges of Driverless Cars, The Conversation. Retrieved January 4, 2019, from https://theconversation.com/who-or-what-is-behind-the-wheelthe-regulatory-challenges-of-driverless-cars-55434

Du, W., Pan, S. L., Zhou, N., \& Ouyang, T. (2018) From a marketplace of electronics to a digital entrepreneurial ecosystem (DEE): The emergence of a meta-organization in Zhongguancun, China. Information Systems Journal, 28 (6): 1158-1175.

Groopman, J., Lieb, R., Owyang, J., \& Szymanski, J. (2017). Three Macrotrends Impacting the Journey to 2030, Kaleido Insights, http://www.kaleidoinsights.com/jeremiah/report.pdf

Helfat, C. E. \& Raubitschek, R. S. (2018). Dynamic and integrative capabilities for profiting from innovation in digital platform-based ecosystems. Research Policy, 47 (8): 1391-1399.

Hellwig, C. (2017). New Perspectives on Cyber Security: The Regulatory Challenge, Global Risk. Retrieved February 6, 2019, from Insights.https://globalriskinsights.com/2017/05/new-perspectives-cyber-securityregulatory-challenge/

Henderson, J. V. (1995). Not a funeral but a wake: regional science in perspective. International Regional Science Review, 17 (3): 333-36.

Ho, J-Y. (2014). Standardization Roadmapping: Cases of ICT Systems Standards, STI Policy Review, 5 (1): 133.

Hollands, R.G. (2008). Will the Real Smart City Please Stand up? City, 12(3): 303-20. 
Hoover, E. M. (1975). An Introduction to Regional Economics. 2nd. Ed. NY: Alfred A. Knopf.

Isenberg, D. J. (2011) Introducing the Entrepreneurship Ecosystem: Four Defining Characteristics, Forbes. Retrieved March 1, 2019, from http://www.forbes.com/sites/danisenberg/2011/05/25/introducing-theentrepreneurship-ecosystemfour-defining-characteristics/

Katz, B. \& Wagner, J. (2014). The Rise of Innovation Districts: A New Geography of Innovation in America. Washington, D.C. USA: Brookings Institute.

Kumar P. A. (2017) Customer Experience Trends in Digital Transformations, CapGemini. Retrieved December 20, 2018, from https://www.capgemini.com/2017/11/customer-experience-trends-in-digital-transformations/

Kriz, A., Molloy, C., Kriz, A., \& Sonntag, S. (2016). All Australian regions are not born equal: understanding the regional innovation management sandpit, Technology Innovation Management Review, 6 (6): 11-23.

Lee, J.H., Phaal, R., \& Lee, S-H. (2013). An integrated service-device-technology roadmap for smart city development, Technological Forecasting \& Social Change 80: 286-306.

Leydesdorff, L. \& Deakin, M. (2011). The triple-helix model of smart cities: A neo-evolutionary perspective. Journal of Urban Technology, 18 (2): 53-63.

Manyika, J., Chui, M., Miremadi, M., Bughin, J., George, K., Willmot, P., \& Dewhurst, M. (2017) A Future that Works: Employment, Automation and Productivity, McKinsey Global Institute.

Marshall, A. (1898). Principles of Economics. 4th. Ed. London: Macmillan.

Newman, D. (2017). Top 10 Trends for Digital Transformation in 2018, Forbes. Retrieved January 6, 2019. https://www.forbes.com/sites/danielnewman/2017/09/26/top-10-trends-for-digital-transformation-in2018/\#358985ee293a

Oh, D. S. Phillips, F., Park, S., \& Lee, E. (2016). Innovation Ecosystems: A Critical Examination. Technovation, 54: $1-6$.

OECD (2013) Innovation-driven Growth in Regions: The Role of Smart Specialisation. Paris: OECD.

Phaal, R., Farrukh, C. J. P., \& Probert, D. R. (2010). Roadmapping for strategy and innovation. Cambridge: Institute for Manufacturing.

Phillips, F. (2006). Social Culture and High Tech Economic Development: The Technopolis Columns. London: Palgrave Macmillan.

Radosevic, S. \& Stancova, K. C. (2018). Internationalising smart specialisation: Assessment and issues in the case of EU new member states, Journal of the Knowledge Economy, 9 (1): 263-293.

Richardson, H. W. (1995). Economies and Diseconomies of Agglomeration. In ed. Giersch, H. Urban Agglomeration and Economic Growth. Kiel: Springer.

Rissola, G. \& Sörvik, J. (2018). Digital Innovation Hubs in Smart Specialisation Strategies Early lessons from European regions. European Commission. ISBN 978-92-79-94829-9

Rodrik, D. (2008) One economics, many recipes: globalization, institutions, and economic growth. Princeton University Press.

Roger, M., Florida, R., Pogue, M., \& Mellander, C. (2015) Creativity, clusters and the competitive advantage of cities, Competitiveness Review, 25 (5): 482-96, 
Schumpeter, J. A. (1934). The Theory of Economic Development. Cambridge, MA: Harvard University Press.

Schlaepger, R., Koch, M., \& Merkofer, P. (2014). Industry 4.0 - Challenges and Solutions for the Digital Transformation and Use of Exponential Technologies, Deloitte Report.

Sussan, F. \& Acs, Z. (2017) The digital entrepreneurial ecosystem, Small Business Economics, 49 (1): 55-73.

Stam, S. (2015). Entrepreneurial ecosystems and regional policy: A sympathetic critique, European Planning Studies, 23 (9): 1759-69.

Stam, E. (2018). Enabling Creative Destruction: An Entrepreneurial Ecosystem Approach to Policy, University Of Utrecht, Working Paper Series Number: 18-05.

Tan, B., Pan, S. L., Xianghua, L. \& Lihua, H. (2015). The role of IS capabilities in the development of multisided platforms: The digital ecosystem strategy of alibaba.com, Journal of the Association for Information Systems, 16 (4): 248-280.

Teece, T. J. (2018). Profiting from innovation in the digital economy: standards, complementary assets, and business models in the wireless world. Research Policy, 47 (8), 1367-1387.

Thurik, R., Stam, E., \& Audretsch, D. 2013. The rise of the entrepreneurial economy and the future of dynamic capitalism, Technovation, 33 (8-9): 302-310.

UN (2017). World Cities Report 2016. UN: New York.

Weill, P. \& Woerner, S. (2018). Surviving in an increasingly digital ecosystem. MIT Sloan Management Review, 59 (2): 38-38.

World Economic Forum (2013). Entrepreneurial Ecosystems around the Globe and Company Growth Dynamics. Davos: World Economic Forum. 